\title{
Supplier's cooperation strategy with two competing manufacturers under wholesale price discount contract considering technology investment
}

\section{Shanxue Yang}

Xidian University

Hongwei Liu

Xidian University

Guoli Wang

Tianjin University of Science and Technology

Yifei Hao ( $\nabla$ haoyf@ctbu.edu.cn )

Chongqing Technology and Business University https://orcid.org/0000-0002-3691-4475

\section{Research Article}

Keywords: Supply chain management, Technology investment, Game theory, Wholesale price discount contract

Posted Date: April 13th, 2021

DOl: https://doi.org/10.21203/rs.3.rs-411779/v1

License: (9) (1) This work is licensed under a Creative Commons Attribution 4.0 International License. Read Full License 


\section{Abstract}

Cooperation between upstream suppliers and downstream manufacturers in technology investment is a popular way to improve production technology for reducing suppliers' production costs of key components. Technology investments undertaken by manufacturers and wholesale price discount contract provided by suppliers have an important impact on their cooperation. This paper explores whether a supplier should cooperate with two downstream competing manufacturers to accept their technology investments to reduce the supplier's production cost of a key component. Specifically, we consider the following three cooperation strategies: the supplier does not accept manufacturers' technology investments, only accepts one manufacturer's technology investment and accepts both manufacturers' technology investments. Our results demonstrate that the wholesale price discount contract and the technology investment can enhance the profits of the supplier and two manufacturers when the discount degree is low. Further, we conclude that when the discount degree is relatively low or when the discount degree and the technology investment efficiency are relatively high, the supplier's optimal cooperation strategy with two manufacturers is to accept both manufacturers' technology investments for reducing the supplier's production cost of the key component and both manufacturers are also willing to invest simultaneously. At last, we extend the model to the asymmetric potential market size and show that our theoretical results are robust.

\section{Full Text}

Due to technical limitations, full-text HTML conversion of this manuscript could not be completed. However, the manuscript can be downloaded and accessed as a PDF.

\section{Figures}




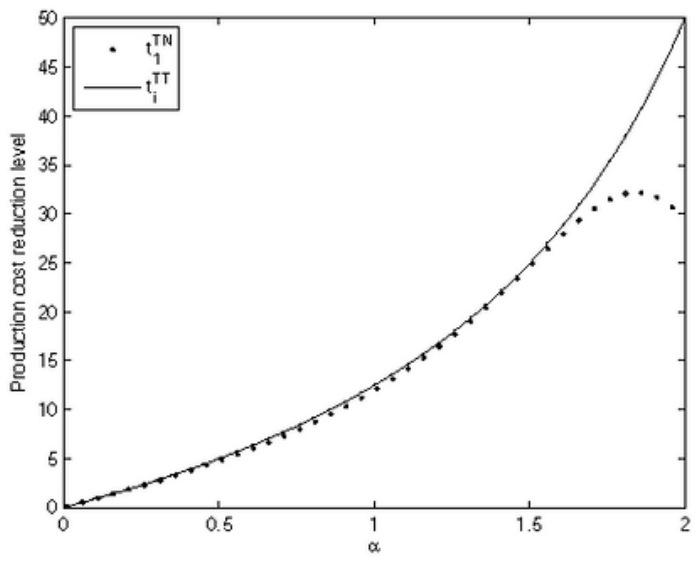

(a) Effects of $\alpha$ on production cost reduction levels

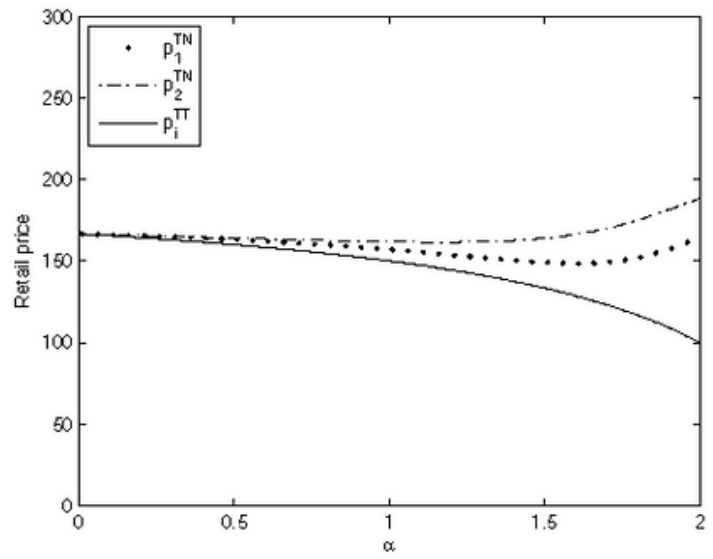

(c) Effects of $\alpha$ on the retail prices

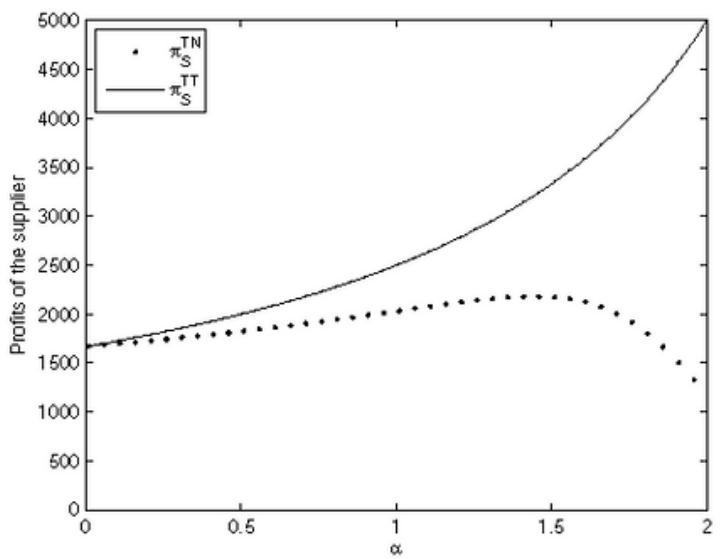

(e) Effects of $\alpha$ on the supplier's profit

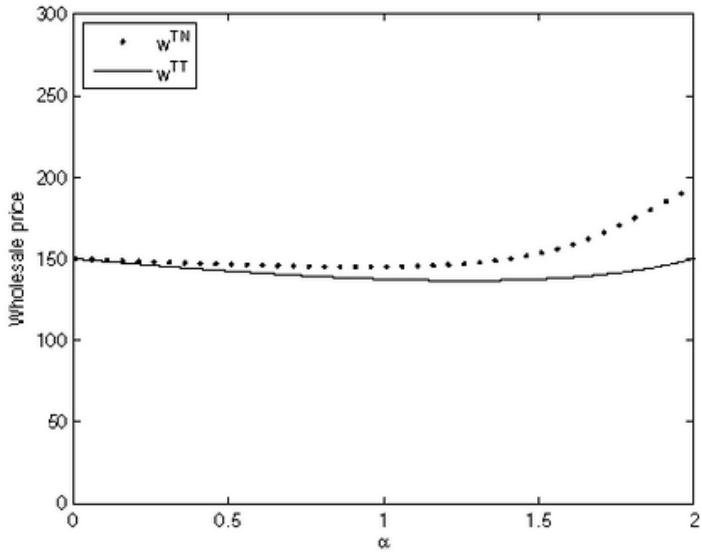

(b) Effects of $\alpha$ on the wholesale prices

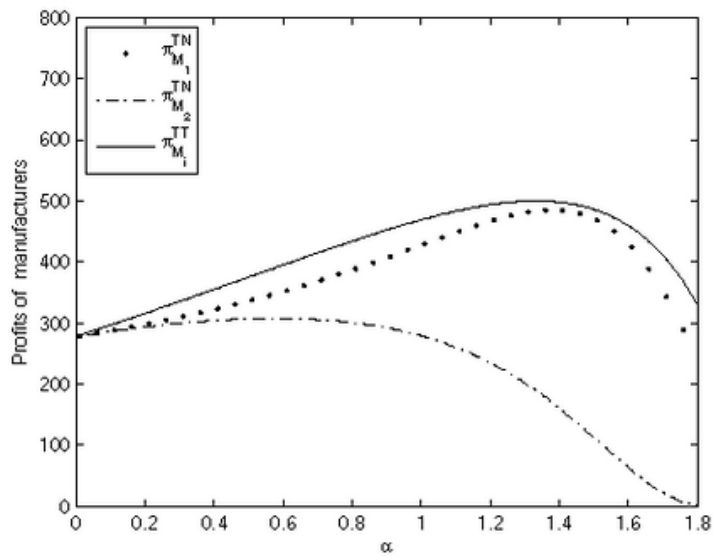

(d) Effects of $\alpha$ on manufacturers' profits

\section{Figure 1}

Effects of $a$ on the optimal decision variables and profits 


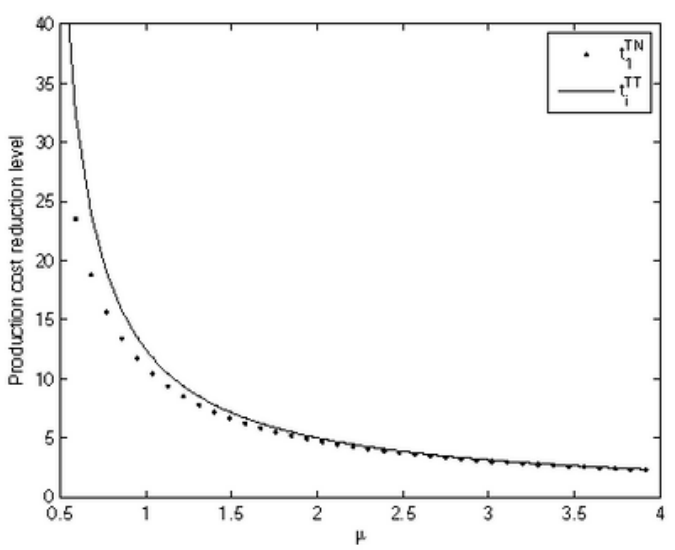

(a) Effects of $\mu$ on production cost reduction levels

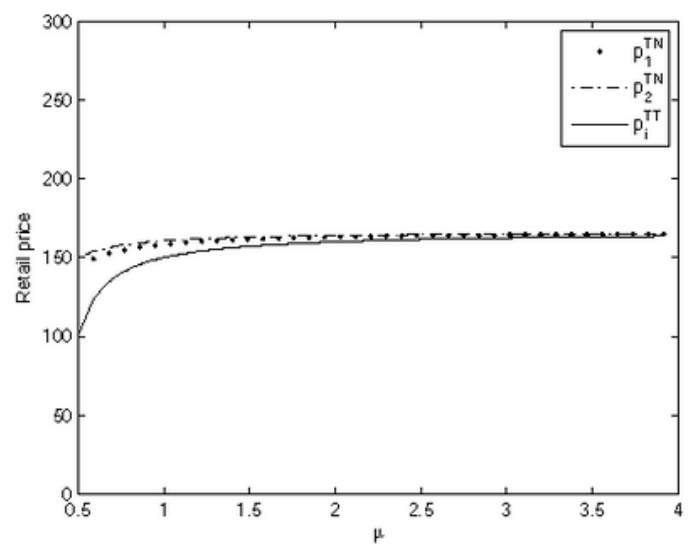

(c) Effects of $\mu$ on the retail prices

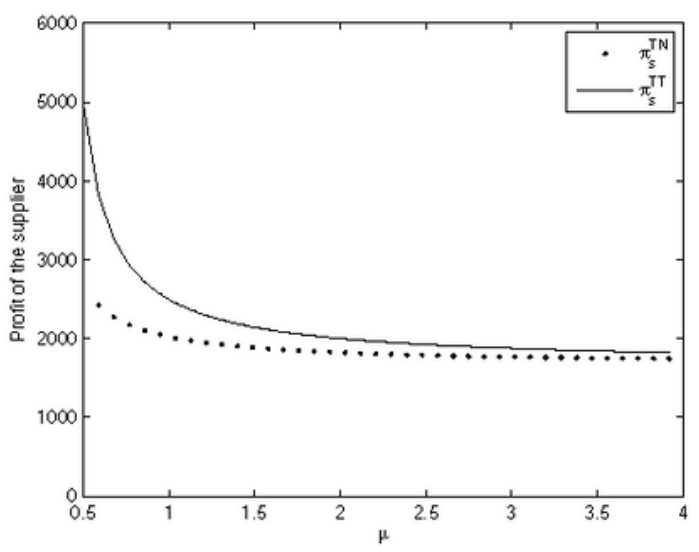

(e) Effects of $\mu$ on the supplier's profits

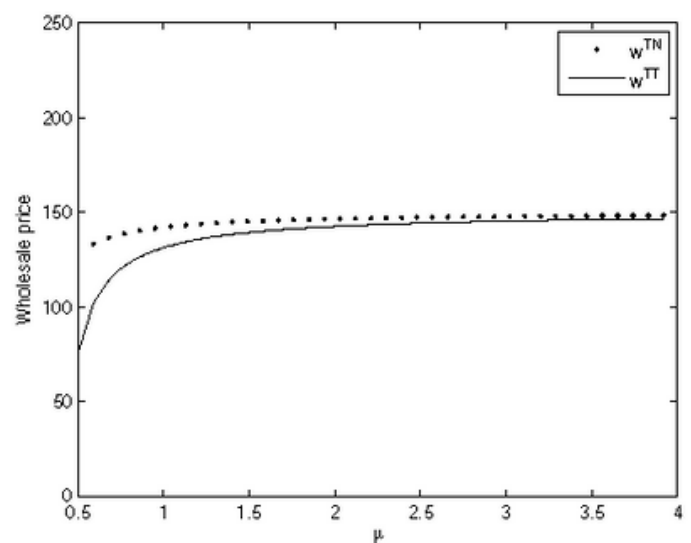

(b) Effects of $\mu$ on the wholesale prices

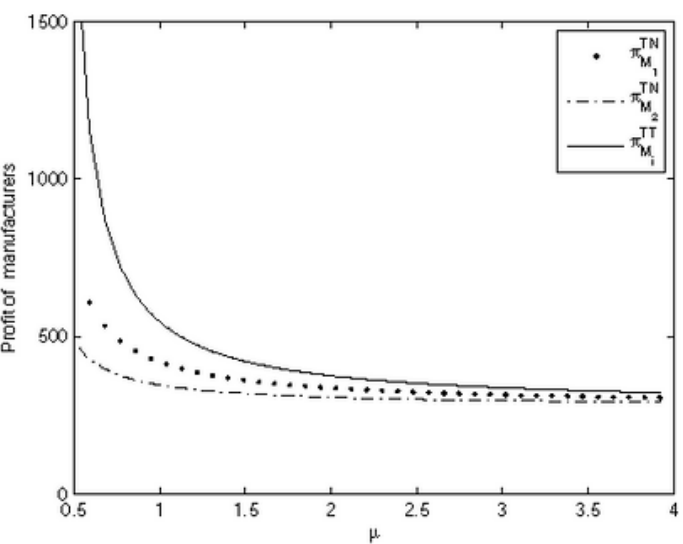

(d) Effects of $\mu$ on manufacturers' profits

\section{Figure 2}

Effects of $\mu$ on the optimal decision variables and profits 


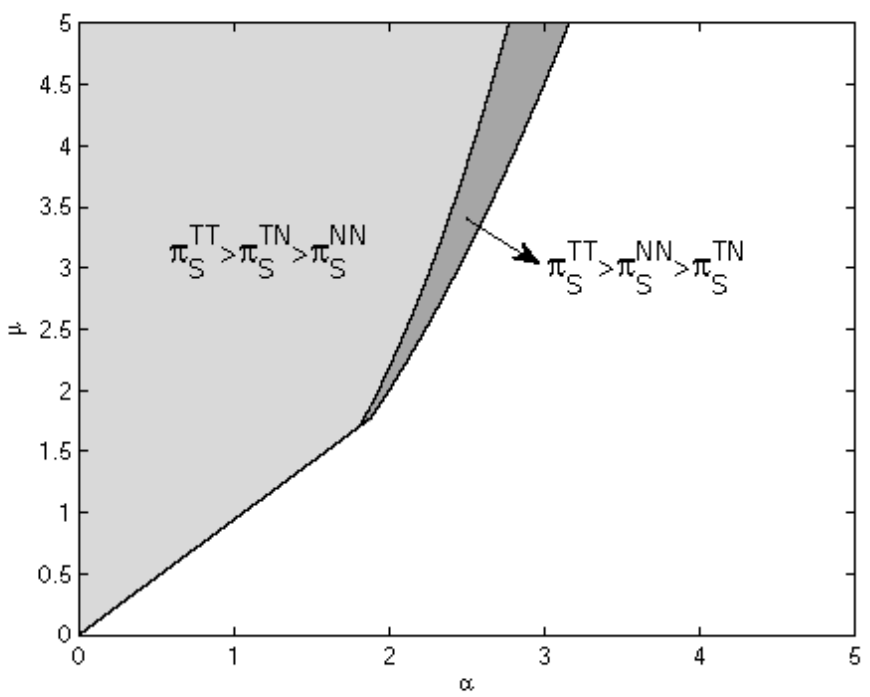

(a) $\mathrm{b}=0.2$

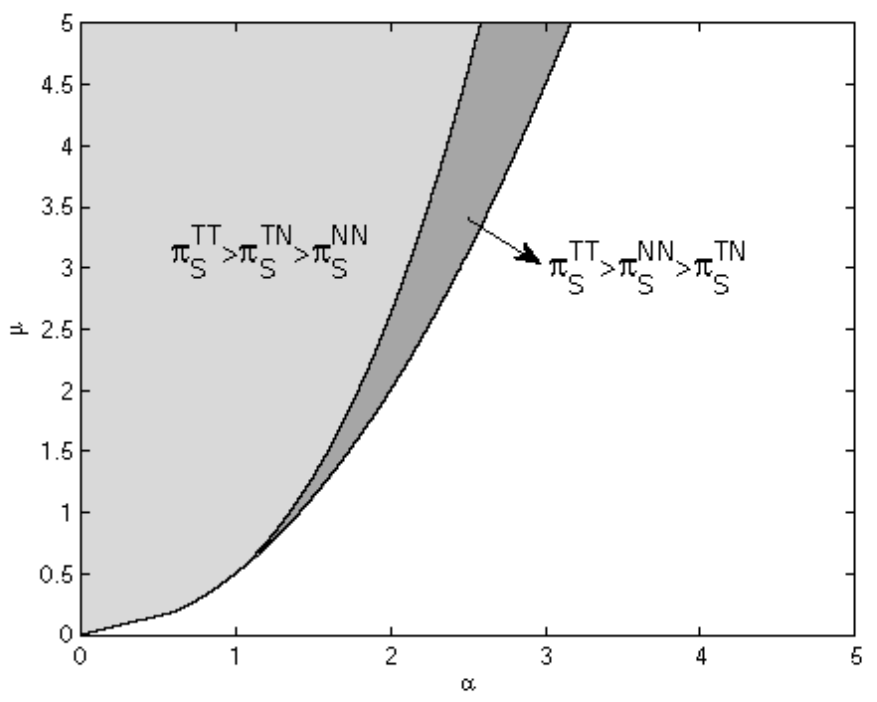

(b) $b=0.9$

Figure 3

Comparisons of the supplier's profits in cases NN,TN and TT

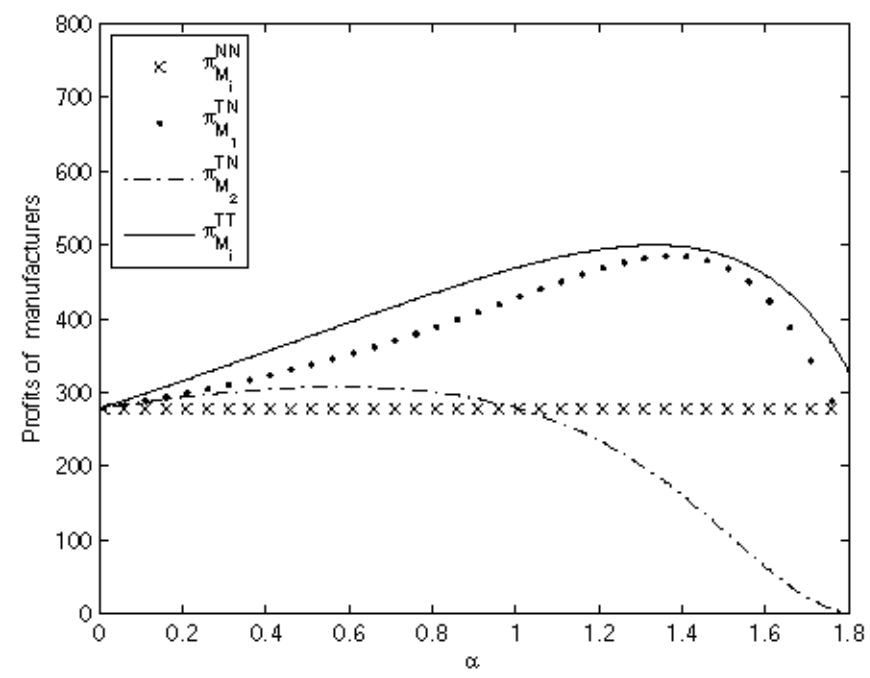

(a) $\mu=2$

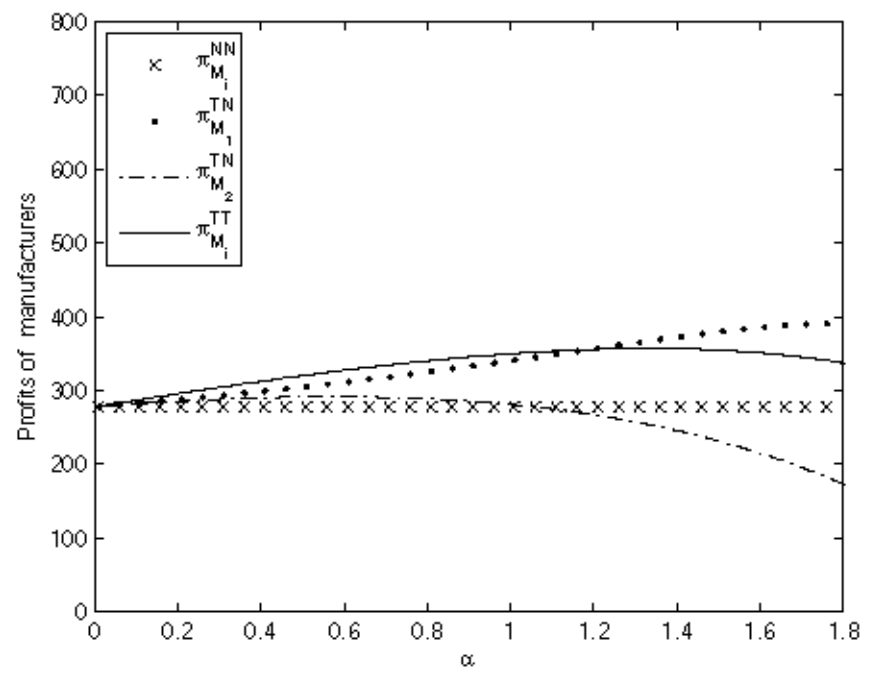

(b) $\mu=4$

Figure 4

Comparisons of two manufacturers' profits in cases NN,TN and TT 